\title{
Integration Monitoring of On-grid Photovoltaic System: Case Study
}

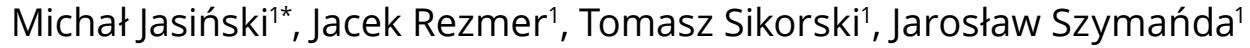 \\ 1 Department of Electrical Engineering Fundamentals, Faculty of Electrical Engineering, \\ Wrocław University of Science and Technology, 50-370 Wrocław, Wybrzeże Wyspiańskiego 27, Poland \\ * Corresponding author, e-mail: michal.jasinski@pwr.edu.pl
}

Received: 08 November 2018, Accepted: 23 January 2019, Published online: 26 March 2019

\begin{abstract}
The aim of the paper is to present possible using of monitoring systems associated with photovoltaic systems (PV) in point of its integration with electrical power system (EPS). Presented investigations is a case study of $15 \mathrm{~kW}$ Scientific Photovoltaic System. The paper contains a description of applied control and monitoring systems including monitoring of PV panels parameters, weather condition, PV DC/AC inverters as well as special monitoring systems dedicated to power quality (PQ) and shape of voltage and current. The aim of the paper is to exhibit a possibility to combine different monitoring systems of the PV in order to improve evaluation of integration of PV with EPS. Presented example contains selected elements of power quality assessment, power and energy production, weather conditions for selected period of PV system working time.
\end{abstract}

Keywords

photovoltaic, distributed energy resources, electrical network parameters, power quality, monitoring systems

\section{Introduction}

The approach to electric energy has changed over the years. One of the currently developed energy sectors is related to distributed energy resources (DER). In order to control the process of the connection of DER to electrical power system (EPS), different monitoring systems might be applied. One of the crucial examples is the system for measure and analysis of power quality (PQ) in point of common coupling (PCC) of DER. Other systems are dedicated to monitoring of weather conditions, technical parameters of PV panels like temperature as well as state of the work and regulation of DC/AC converters. The authors see a need for integration of the monitoring systems for suitable evaluation of integration of DER with EPS.

The paper presents an example of the control and monitoring systems of a $15 \mathrm{~kW}$ photovoltaic system with its application in evaluation of the integration of the PV system with EPS. The system includes monitoring of PV panels parameters, weather condition, PV DC/AC inverters as well as special monitoring systems dedicated to power quality (PQ) or voltage and current shape. Presented examples of the monitoring systems possible using contain power quality assessment, power and energy production, weather conditions.

\section{PV system monitoring - state of the art}

The PV monitoring issues are often described in the literature. The following part of the chapter contains the examples of articles which concern the PV system evaluation based on different monitoring systems.

Article [1] is an overview of quality assurance measures for large-scale PV power plants. The paper contains the discussion related to yield monitoring and assessment, module and on-site system testing, power rating. The procedure for the analysis of module and system long-term stability using performance monitoring data of systems was presented. The paper authors highlight that present high-performance ratio indicates that solar PV is highly reliable and well-performing technology.

Article [2] presents the data acquisition system to monitor the wind speed, solar irradiation, and PV temperature. The system is based on a low-cost AVR microcontroller. Proposed system may be a substitute to pyranometer, anemometer and thermometer. The great advantage of the proposed data acquisition system is the possibility to connect with SCADA system. Using described in article system provides useful information about the environmental conditions for operating the hybrid power system effectively. Presented in the article, data acquisition system was 
tested in comparison to standard measure devices. The measurement errors were lower than $5 \%$.

Paper [3] presents the evaluation of grids power quality in low voltage network with small sized photovoltaic. The power quality monitor system (PQMS) has been designed to realize the evaluation. The $200 \mathrm{~ms}$ data were collected for four months in server. The PQ database obtained by the used PQMS allows for detailed analysis of the impact of PV on the local network.

Article [4] presents the problem of PV monitoring. Authors indicate, that PV parameters such as open-circuit voltage, short-circuit current, power, energy yield are measured and monitored remotely. But on the other hand, authors indicates the lack of parameters monitoring related to the state of the connections, switches, wire coatings, stability of mounts as a function of time. The extended analysis is expected to provide guidelines to devise accelerated tests for achieving longer life of PV systems.

Article [5] presents the results of building integrated photovoltaic (BIPV) system monitoring. The BIPV system consists of $20 \mathrm{~kW}$ photovoltaic generator and three-phase inverter. The system was installed in Columbia. The performance and power quality of BIPV were measured and analyzed. The article presents the results of correlation of performance with metrological and solar radiation data. Also, the paper contains the monitoring results in 2016 which consist of performance of PV array and inverter as well as analysis of system efficiency, production of electrical energy, power quality level. The chosen standard to the PQ assessment of PV system was IEEE-929-2000.

Article [6] contains the power quality assessment in PCC to power grid of PV system and in the PV station network terminal. The annual PV power generation is 3647MWh. The analyzed PQ parameters are harmonic, voltage imbalance, and frequency deviation. The results of the article show that the analyzed PV system is running well, and its access has no adverse effect on the power quality of the grid. Presented in the article test and analysis provide a reference for the monitoring and analysis of power quality of photovoltaic grid-connected power grid.

\section{Power quality parameters}

The assessment of PQ became a good practice in the assessment of quality of the supply in EPS. The basic assessment depends on the agreement between operator and customer, regulations and standards. The main European standards related to PQ are EN 50160 [7] and IEC 61000 3-30 [8]. Comparable IEEE standard is IEEE P1159 [9]. Additionally, in the case of companies with meaningful energy consumption, it is possible to define the acceptance level especially for an individual company which may differ from general regulations. PQ parameters can be generally divided into 2 groups: voltage variations and voltage events [10]. Voltage events are rapid voltage changes, voltage dips, swells, temporary overvoltage, transient overvoltage, interruptions. Voltage variations are frequency, voltage changes, voltage fluctuation, voltage unbalance, harmonic and interharmonic, communication notches, voltage signaling. The voltage variations form a set of PQ parameters aggregated in 10-minute or 2-hour which represent a normal operating working condition of the electrical network. The parameters which are taking into assessment according to EN 50160 standard [7] are:

- frequency level - f [Hz],

- voltage level - U [V],

- voltage unbalance - k2u [\%],

- voltage fluctuation: short-term flicker severity - Pst [-], long-term flicker severity - Plt [-]

- harmonic content: Total Harmonic Distortion in voltage - THDu [\%], the content of each harmonic from 2 nd to 50 th - h2-h50 [\%].

The demands for each power quality parameter level are defined in EN 50160 standard [7] for the different level of voltage. Some updates of the permissible levels were stated in amendment to [7] in 2015. Described in this article PV system is connected to low voltage. Referring to the last amendment of EN 50160 standard [7] the demands for LV system can be defined as follow:

- The system frequency shall be within $49.9 \div 50.1 \mathrm{~Hz}$ for $100 \%$ of the time.

- The $1-$ min values of voltage shall be within $207 \div 253 \mathrm{~V}$ for $100 \%$ of the time. Although this demand is not introduced to PQ recorders (1-min averaging) so previous demands are used, it means that 10 -min averaging data are the basement for the assessment.

- The 10-min values of short-term flicker shall be lower than 1.2 for $95 \%$ of time.

- The 2-h values of long-term flicker shall be lower than 1.0 for $100 \%$ of time.

- The 10-min values of THDu shall be lower than $8 \%$ for $100 \%$ of time. Additionally, the mean value of all THDu values shall be lower than $5 \%$.

- The 10-min values of each harmonic (h) harmonic for $100 \%$ of time shall be lower than:

- $6.0 \%$ for $5 \mathrm{~h}$; 
- $5.0 \%$ for $3 \mathrm{~h}, 7 \mathrm{~h}$;

- $3.5 \%$ for $11 \mathrm{~h}$;

- $3.0 \%$ for $13 \mathrm{~h}$;

- $2.0 \%$ for $2 \mathrm{~h}, 17 \mathrm{~h}$;

- $1.5 \%$ for $9 \mathrm{~h}, 19 \mathrm{~h}, 23 \mathrm{~h}, 25 \mathrm{~h}$;

- $1.0 \%$ for $4 \mathrm{~h}, 29 \mathrm{~h}, 31 \mathrm{~h}, 35 \mathrm{~h}, 37 \mathrm{~h}, 41 \mathrm{~h}, 43 \mathrm{~h}, 47 \mathrm{~h}, 49 \mathrm{~h}$;

- $0.5 \%$ for $6 \mathrm{~h}, 8 \mathrm{~h}, 10 \mathrm{~h}, 12 \mathrm{~h}, 14 \mathrm{~h}, 15 \mathrm{~h}, 16 \mathrm{~h}, 18 \mathrm{~h}, 20 \mathrm{~h}$, 21h, 22h, 24h, 26h, 27h, 28h, 30h, 32h, 33h, 34h, 36h, 38h, 39h, 40h, 42h, 44h, 45h, 46h, 48h, 50h.

The assessment of PQ is made separately for each parameter [11]. The extension of permissible level of one parameter indicates that the level of power quality is not satisfied.

\section{PV \& data system}

The analyzed PV system consists of three independent one-phase systems. The maximum power of installation is $15 \mathrm{~kW}$ and particular one-phase subsystems have a $5 \mathrm{~kW}$ each. Described PV subsystems use different types of PV technologies: monocrystalline (MONO), thin layer copper indium gallium selenide (CIGS), polycrystalline (POLY). Table 1 presents the detailed information about the subsystems of the investigated PV installation. The photovoltaic installation is located at roof of one of the University building. The view of the PV installation and is presented in Fig. 1. The installation is connected directly to a substation equipped with a $20 \mathrm{kV} / 0.4 \mathrm{kV} 630 \mathrm{kVA}$ transformer. The phase location of the PV subsystems is:

- L1 - cigs,

- L2 - mono,

- L3 - poly.

The monitoring system of the PV installation consists of 3 basic elements. The first element is the power quality recorder. The second system is for the acquisition of raw data of voltage and current waveform. The third source of data comes for the control system of PV DC/AC converters. The view of the monitoring system station is presented in Fig. 2. PQ recorder collects the power quality parameters in accordance with the demands of class $A$ of EN 61000 4-30 standard [8]. PQ measurement data is collected in database since 2016. The data are divided into six subgroups. The subgroups contain the voltage deviation and voltage events data: oscilloscope data with $10 \mathrm{kHz}$ sampling, $10 \mathrm{~ms}$ RMS values, $200 \mathrm{~ms}$ frequency spectrum, 10 minutes aggregated data, 2 hours aggregated data, 1 day aggregated data. Control systems of PV
Table 1 Features of PV subsystems [12]

\begin{tabular}{lccc}
\hline Parameter & \multicolumn{3}{c}{ PV subsystem } \\
\hline Cell type & "mono" & "cigs" & "poly" \\
Azimuth & $135^{\circ} \mathrm{SE}$ & $135^{\circ} \mathrm{SE}$ & $225^{\circ} \mathrm{SW}$ \\
$\begin{array}{l}\text { Modules number } \\
\begin{array}{l}\text { Module maximum } \\
\text { power }\end{array}\end{array}$ & 27 & 56 & 21 \\
\hline
\end{tabular}

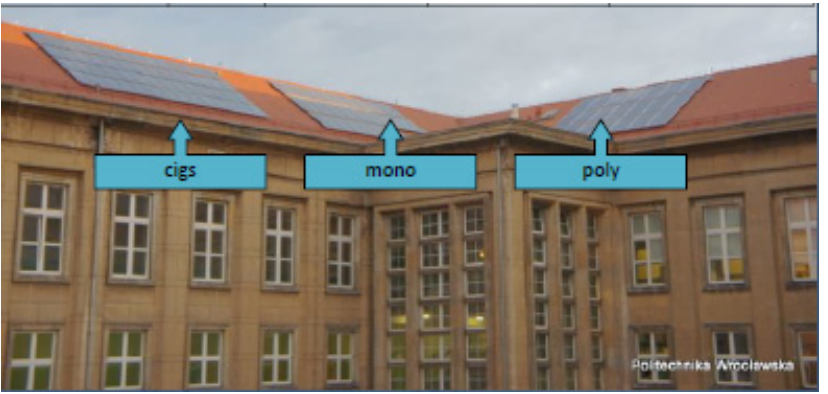

Fig. 1 The view of PV installation at the University building [13].

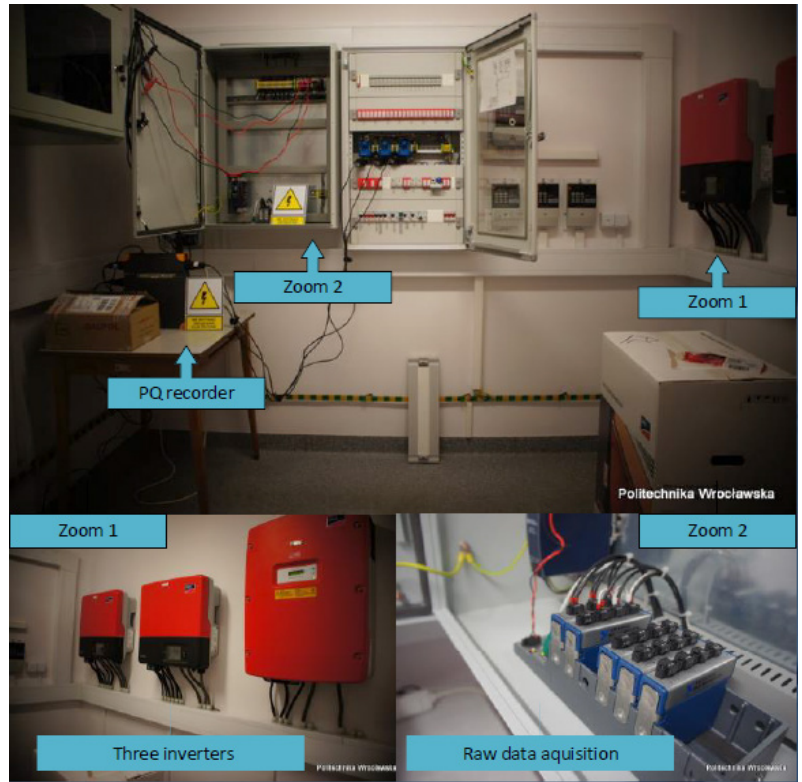

Fig. 2 The view of PV installation monitoring system at the University building [13].

converters monitor power and energy level in both $\mathrm{AC}$ and DC side. The PV system inverters are two transformer less (mono, poly) and one with transformer (cigs). Raw data acquisition system allows storing a digital sample of voltage and current waveform that might be useful in analysis of events when the waveform of voltage and currents gives information about the type of event. The system is based on National Instruments components.

Due to a wide range of applied monitoring systems, it is possible to make an investigation of influence of different working condition of the PV system on power quality in 
the PCC, energy production, dynamic states of the integration with electricity network. Additionally, all the data are stored in databases so the long term analysis of the data stored in mentioned monitoring systems are possible.

\section{Evaluation of PV system working in PCC}

Presented in this work evaluation of integration of the PV system with EPS is based on PQ, power and energy analysis. A one week of data recorded in May 2018 was selected. This time range was selected because in Poland 1st-3rd of May was a holiday and 4th-7th were working days. Such selection assured different load demands during observed time. Collected data represents the different working condition of electrical power network [14]. In case of long term data analysis a power and energy analysis are presented. The analysis is based on control and monitoring system information of PV DC/AC converters. Examples contain monthly and annual analysis of 2018.

The power quality parameter waveforms are presented in Figs. 3-8. Each figure contains additionally the waveform of the active power in PCC. It indicates to the changeability of the parameter in accordance with one-phase PV subsystems power production. The analysis of the University PV installation PQ level are made separately for each parameter in accordance to LV level demands of the standards and regulations [15].

First analyzed PQ parameter is frequency. Fig. 3 presents the frequency changes in the selected week time. The frequency level is on acceptance level in accordance to the EN 50160 standard [7]. The level of frequency deviations are small and not exceed the $0.07 \mathrm{~Hz}$. Frequency is the system parameter and observed PV has no impact on it.

Second analyzed PQ parameter is voltage level. Fig. 4 presents the voltage variations in the selected week time. The voltage level is on acceptance level in accordance to the EN 50160 standard [7]. The voltage level in PCC is noticeable higher than the declared $230 \mathrm{~V}$ but lower than permissible limit equal to $253 \mathrm{~V}$. Voltage changes represent rather daily character of the network than the impact of PV.

The next analyzed PQ parameter is voltage fluctuation. The voltage fluctuations are represented by two parameters: short term and long term flicker severity. Fig. 5 presents the short term flicker waveform and Fig. 6 presents the long term flicker in the selected week time. Both flicker severities are on acceptance level in accordance to the EN 50160 standard [7]. The sensitivity for single disturbances of the long term flicker severity is smaller than the short term. It's important to notice that the higher level

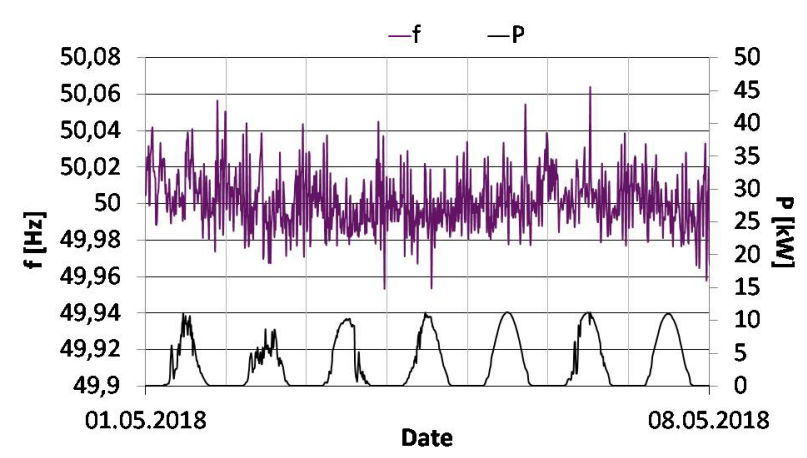

Fig. 3 Frequency (f) and active power from 3-phases (P) deviations in PCC of PV system.

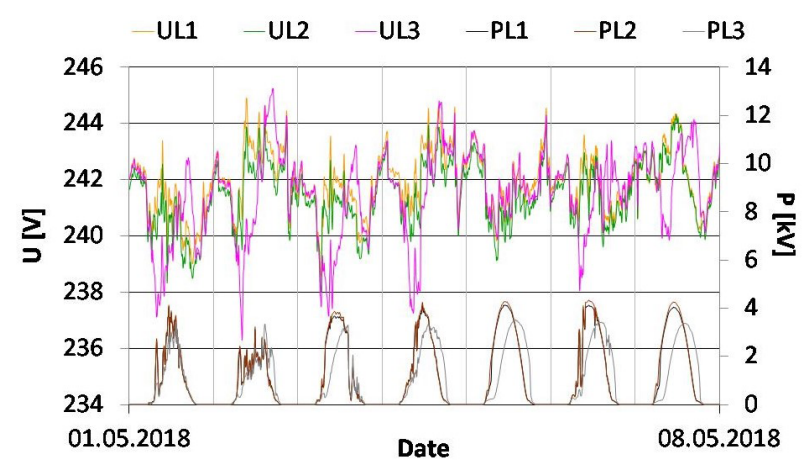

Fig. 4 Voltage level (U) and active power (P) deviations in PCC of PV system. L1 - represents cigs subsystem, L2 - represents mono subsystem, L3 - represents ploy subsystem.

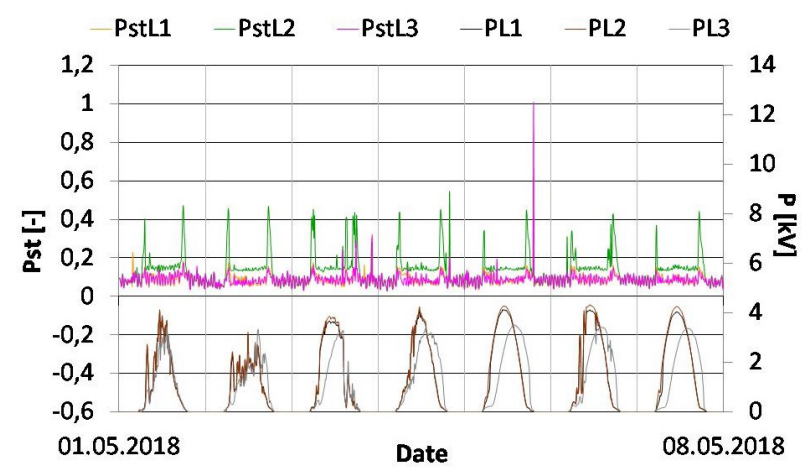

Fig. 5 Short term flicker severity (Pst) and active power (P) deviations in PCC of PV system. L1 - represents cigs subsystem, L2 - represents mono subsystem, L3 - represents ploy subsystem.

was noticed only in phase L3 related to Poly PV panels. There's no information about voltage events in the period of time when the higher fluctuations were noticed in phase L3.

Next analyzed PQ parameter is voltage unbalance. Fig. 7 presents the voltage unbalance variations in the selected week time. The voltage unbalance level is on acceptance level in accordance to the EN 50160 standard [7]. The low value of asymmetry assure the information that even the 


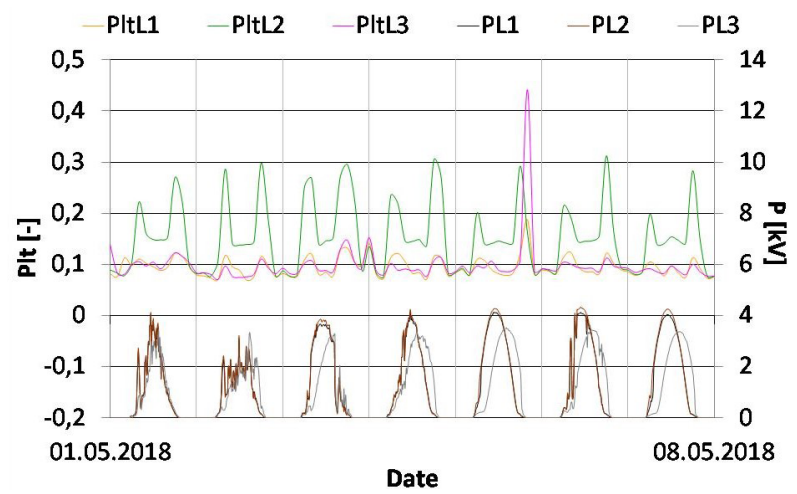

Fig. 6 Long term flicker severity (Plt) and active power $(\mathrm{P})$ deviations in PCC of PV system. L1 - represents cigs subsystem, L2 - represents mono subsystem, L3 - represents ploy subsystem.

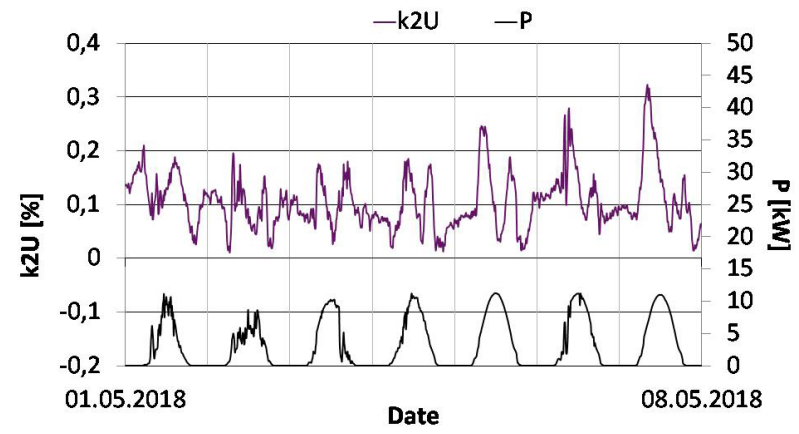

Fig. 7 Voltage unbalance (k2U) and active power from 3-phases (P) deviations in PCC of PV system.

various azimuth of PV panels connected to different phases the asymmetry is on acceptance level. Although the asymmetry level is lower when poly panels produces the energy due to different geographical azimuth (Table 1).

Voltage waveform distortion is assessed using harmonic contribution. The permissible harmonic level is defined separately for each harmonic or one to all - total harmonic distortion in voltage (THDu) Fig. 8 presents the THDu variations in the selected week time. The THDu level and level of each separate harmonic are on acceptance level in accordance with the EN 50160 standard [7]. Harmonic distortion to daily character of the network. Increased parameter THDu during a night follows by non-linear lighting equipment. In comparison the mention impact the PV impact can be omitted.

The power quality assessment in PCC of PV system for all the parameter in accordance to the EN 50160 standard [7] note that the level is on acceptance level.

To indicate the productivity of PV system in long period of time the analysis of energy yield can be performed. The analysis is usually realized in month, year or total period of time from starting PV production [16].

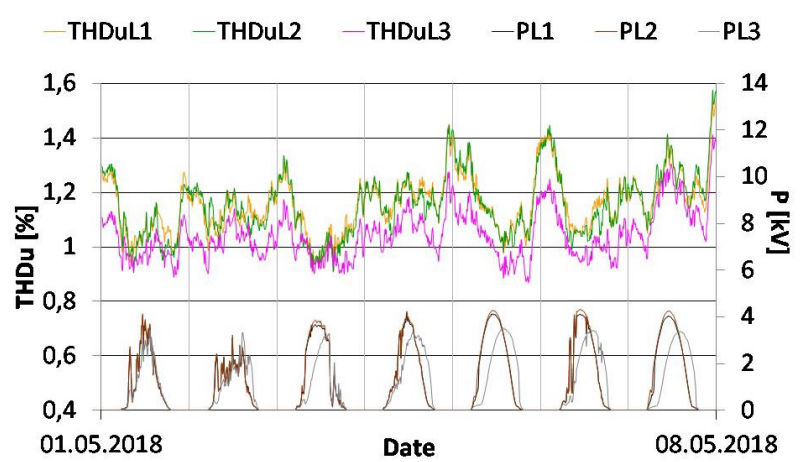

Fig. 8 Total harmonic distortion in voltage (THDu) and active power (P) deviations in PCC of PV system. L1 - represents cigs subsystem, L2 - represents mono subsystem, L3 - represents ploy subsystem.

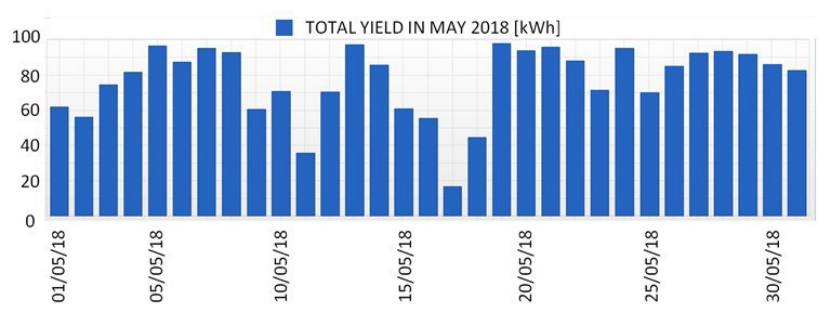

Fig. 9 Total yield in May 2018 of PV system [13].

To correspond to the PQ analysis, a PV production yield in May 2018 is presented in Fig. 9. First 7 days of the May (PQ analyzed period of time) represent the days in which the PV system works efficiently. Thus PV system impact may be noticeable to the grid working conditions.

Fig. 10 presents the total yield and the average yield expectation in the 2018 for the PV system. Depending on the orientation and the irradiation fluctuations between the individual years, there might be considerably larger deviations in contrast to the expected average yield.

Fig. 11 presents the specific yield corresponding to 2018. The selected to analysis month (May) has the highest value of the specific yield. May 2018 is a representant of the situation when the PV system works efficiently. This confirms the correctness of the analyzed period of time selection.

Additionally, the weather conditions are monitored in the PV system. The recorded parameters are temperature of ambiance, temperature of module, wind speed and insolation. The recorded mean values of the parameters in May 2018 are presented in Table 2.

Since the PV system was started, the total yield is measured. The average yield expectations are calculated for each month as a mean value of previous data of PV system working. The calculations are based on all previous measurements. Fig. 12 presents the total yield and average 
Table 2 Weather conditions in May 2018 recorded the PV system weather station

\begin{tabular}{lc}
\hline Parameter & $\begin{array}{c}\text { Mean value of parameter } \\
\text { in month average }\end{array}$ \\
\hline Ambient temperature $\left[{ }^{\circ} \mathrm{C}\right]$ & 20.33 \\
Module temperature $\left[{ }^{\circ} \mathrm{C}\right]$ & 22.51 \\
Insolation $\left[\mathrm{W} / \mathrm{m}^{\wedge} 2\right]$ & 243.42 \\
Wind speed $[\mathrm{m} / \mathrm{s}]$ & 0.91 \\
\hline
\end{tabular}

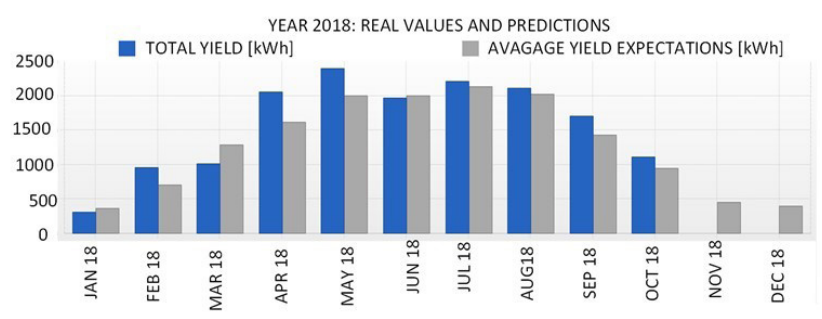

Fig. 10 Total yield and it's exaptation in 2018 of PV system [13].

yield expectation for all period of PV system working. The expectation meets the real values in following years.

\section{Conclusion}

This article presents the possibility of using different monitoring systems of PV installation. Presented example is based on three monitoring systems which are dedicated to the measurement of power quality, work state of $\mathrm{DC} /$ $\mathrm{AC}$ converters as well as weather condition. The systems are installed in PV system in the university campus. The monitoring system assures the long term data of power quality parameters, power and energy production, weather conditions. The main advantage of presented possibility is to combine the data coming from different monitoring

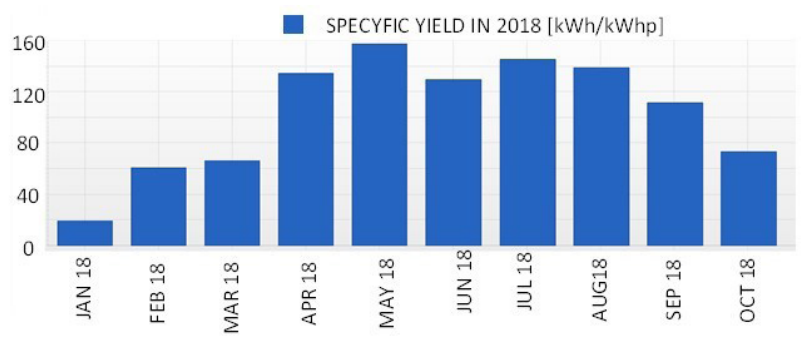

Fig. 11 Specific yield in 2018 of PV system [13].

systems and make a cross-research of the maintenance of the system in different working conditions which might be constituted by different weather condition, different load demand of the power system network. In presented investigation, the detailed power quality analysis period of time was selected on the basis of PV system annual productivity. The analysis of the power quality was related to power production and weather condition. Power quality level in PCC of PV system was on acceptance level according to European standards. Application of descried monitoring systems allowed to detect an influence of the azimuth of the PV on voltage asymmetry. The most sensitive parameter is voltage unbalance but the asymmetry level is appreciated. The calculation of performance expectation connected to the total yield meets the real measured values. Using the monitoring systems it's possible to indicate positive assessment of observed PV installation with electrical power system.

\section{Acknowledgment}

This work was supported by Polish Ministry of Higher Education and Science, project 0401/0049/18.

PV SYSYTEM: REAL VALUES AND PREDICTIONS SINCE 2011

- MEAN TOTAL YIELD [kWh] AVAGAGE YIELD EXPECTATIONS [kWh]

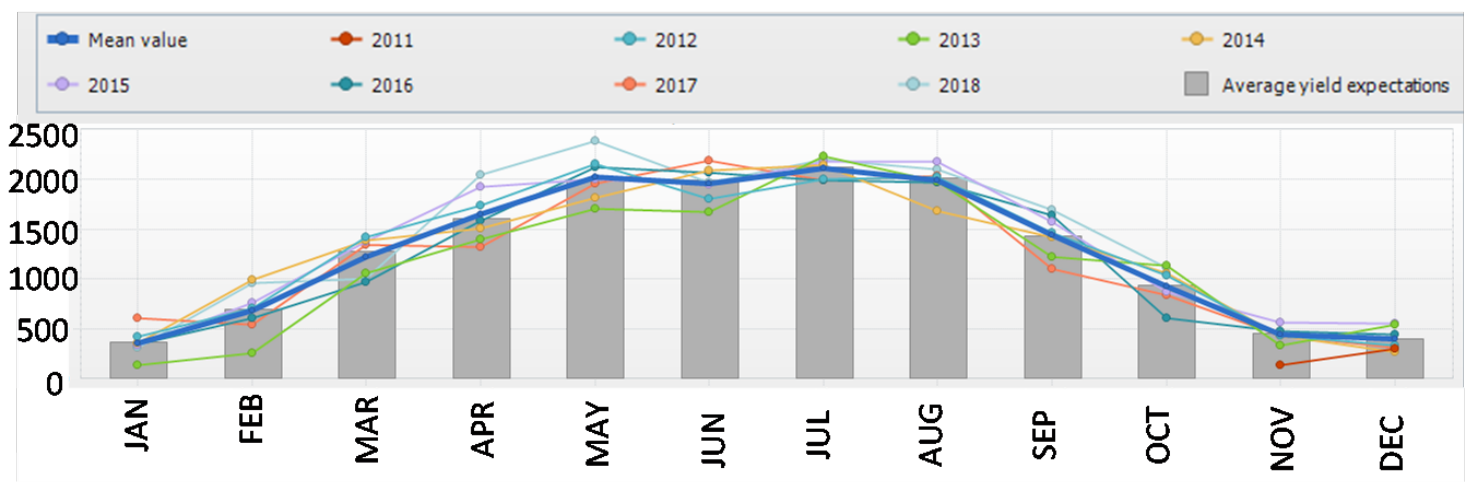

Fig. 12 Total yield and average yield expectation of PV system since 2011 [13]. 


\section{References}

[1] Kiefer, K., Reich, N. H., Dirnberger, D., Reise, C. "Quality assurance of large scale PV power plants" In: 2011 37th IEEE Photovoltaic Specialists Conference, Seattle, WA, USA, 2011, pp. 1987-1992.

https://doi.org/10.1109/PVSC.2011.6186343

[2] Soetedjo, A., Nakhoda, Y. I., Suryadi, D. "Development of data acquisition system for hybrid power plant", In: 2013 International Conference on QiR, Yogyakarta, Indonesia, 2013, pp. 197-201. https://doi.org/10.1109/QiR.2013.6632564

[3] Kandil, S., Farag, H. E., Hilaire, L. S., Janssen, E. "A power quality monitor system for quantifying the effects of photovoltaic penetration on the grid", In: 2015 IEEE 28th Canadian Conference on Electrical and Computer Engineering (CCECE), Halifax, NS, Canada, 2015, pp. 237-241.

https://doi.org/10.1109/CCECE.2015.7129192

[4] Dhere, N. G., Ghaisas S. V., Funde, A., Karve, P. "Photovoltaic system performance monitoring for manufacturing quality assurance", In: 2015 IEEE 42nd Photovoltaic Specialist Conference, PVSC 2015, New Orleans, LA, USA, 2015, pp. 1-4.

https://doi.org/10.1109/PVSC.2015.7355982

[5] Banguero, E., Aristizábal, A. J., Murillo, W. "A Verification Study for Grid-Connected 20 kW Solar PV System Operating in Chocó, Colombia", Energy Procedia, 141, pp. 96-101, 2017.

https://doi.org/10.1016/j.egypro.2017.11.019

[6] Cui, J. I., Siming, H. U. A., Bingbing, Z. O. U., Hua, Z., Chang, D., Guofa, Z., Bo, M. I. N. "Monitoring and Analysis of Power Quality in Photovoltaic Power Generation System", E3S Web of Conferences, 64, p. 6008, 2018.

https://doi.org/10.1051/e3sconf/20186406008

[7] British Standards Institution "BS EN 50160:2010/A1:2015 Voltage characteristics of electricity supplied by public distribution network", BSI, 2015.

[8] International Electrotechnical Commission "IEC 61000-4-30:2015 RLV Electromagnetic compatibility (EMC) - Part 4-30: Testing and measurement techniques - Power quality measurement methods", IEC, 2015.
[9] Institute of Electrical and Electronics Engineers "Monitoring and Definition of Electric Power Quality", IEEE, 2009. https://doi.org/10.1109/IEEESTD.2009.5154067

[10] Jasiński M., Sikorski T., Borkowski K. "Clustering as a tool to support the assessment of power quality in electrical power networks with distributed generation in the mining industry", Electric Power System Research, 166, pp. 52-60, 2019.

https://doi.org/10.1016/j.epsr.2018.09.020

[11] Klajn, A., Bątkiewicz-Pantuła, M. "Application Note - Standard EN 50 160: voltage characteristics of electricity supplied by public electricity networks", European Copper Institute, 2017. [online] Available at: http://www.leonardo-energy.org/resources/335/voltage-characteristics-of-grid-electricity-en-50160-58064bab7363e [Accessed: 03 November 2018]

[12] Janik, P. "Photovoltaic power generation assessment based on advanced signal processing and optimization techniques", Oficyna Wydawnicza Politechniki Wrocławskiej, Wrocław, Poland, 2014.

[13] Wroclaw University of Science and Technology, Department of Electrical Engineering "Scientific Photovoltaic System of Wroclaw University of Science and Technology, Department of Electrical Engineering". [online] Available at: http://www.ipee.pwr.wroc.pl/ BSF.dhtml [Accessed: 03 November 2018]

[14] Jasiński, M., Sikorski, T., Karpiński, J., Zenger, M. "Cluster analysis of long-term power quality data", In: Electric Power Networks (EPNet), Szklarska Poreba, Poland, 2016, pp. 1-6. https://doi.org/10.1109/EPNET.2016.7999348

[15] Grycan, W., Brusiłowicz, B., Kupaj, M. "Photovoltaic farm impact on parameters of power quality and the current legislation", Solar Energy, 165, pp. 189-198, 2018. https://doi.org/10.1016/j.solener.2018.03.016

[16] Kaczorowska, D., Leonowicz, Z., Rezmer, J., Janik, P. "Long term performance of a PV system with monocrystalline PV cells - a case study", In: 2017 IEEE International Conference on Environment and Electrical Engineering and 2017 IEEE Industrial and Commercial Power Systems Europe (EEEIC / I\&CPS Europe), Milan, Italy, 2017, pp. 2526-2533. https://doi.org/10.1109/EEEIC.2017.7977838 